\title{
Imaging in Obstructive Jaundice: What a Radiologist Needs to Know before Doing a Percutaneous Transhepatic Biliary Drainage
}

\author{
Pankaj Gupta ${ }^{1, \odot ~ J y o t i ~ G u p t a ~}{ }^{1} \quad$ Praveen Kumar-M² \\ ${ }^{1}$ Section of Radiology, Department of Gastroenterology, \\ Postgraduate Institute of Medical Education and Research \\ (PGIMER), Chandigarh, India \\ 2Department of Pharmacology, Postgraduate Institute of Medical \\ Education and Research (PGIMER), Chandigarh, India
}

\author{
Address for correspondence Pankaj Gupta, MD, Section of \\ Radiology, Department of Gastroenterology, Postgraduate Institute \\ of Medical Education and Research, Chandigarh 160012, India \\ (e-mail: Pankajgupta959@gmail.com).
}

\begin{abstract}
Percutaneous transhepatic biliary drainage (PTBD) is one of the commonly performed biliary interventions. In patients with obstructive jaundice, PTBD may be a lifesaving

Keywords emergency procedure or may serve as an alternative intervention in patients who fail

- obstructive jaundice to undergo endoscopic drainage or those who are too sick to be considered for endo-

- imaging scopic drainage. The key factor in technical and clinical success of PTBD is a thorough preprocedure imaging evaluation. In this review, we highlight the imaging aspects that

- percutaneous transhepatic biliary drainage should be evaluated and reported by a radiologist when evaluating a patient planned for biliary drainage.
\end{abstract}

\section{Introduction}

Obstructive jaundice is a type of jaundice which occurs due to a mechanical obstruction in the biliary drainage pathways. ${ }^{1}$ It is not a disease per se but is the manifestation of some underlying disease process. It can present with acute symptoms or gradually progressive indolent course depending upon the underlying cause. ${ }^{2}$ Percutaneous transhepatic biliary drainage (PTBD) is a minimally invasive procedure for drainage of the biliary system. ${ }^{3}$ PTBD is preferred as the primary procedure in patients who have had prior bilio-enteric anastomosis, or those who are unsuitable for endoscopic retrograde cholangiopancreatography (ERCP) due to other reasons. Imaging plays an essential role in the diagnosis of underlying etiology and provides a road map for the procedures. ${ }^{4}$ Imaging modalities for evaluation of biliary tree are ultrasonography (US), endoscopic ultrasound (EUS), computed tomography (CT), and magnetic resonance imaging (MRI)/MR cholangiopancreatography (MRCP). ${ }^{5}$ In this review article, we highlight the important imaging aspects that should be evaluated by a radiologist in a patient being planned for biliary drainage.

Published online

February 04, 2020
DOI https://doi.org/

$10.1055 / \mathrm{s}-0039-3401327$

ISSN 2457-0214.

\section{Causes of Obstructive Jaundice}

Any obstruction starting from the level of intrahepatic biliary radicles till the ampulla of Vater either intrinsic or extrinsic can cause obstructive jaundice. These can be divided into congenital causes like a choledochal cyst, postoperative strictures, and inflammatory causes like post inflammatory ampullary stricture, choledocholithiasis, neoplastic etiologies like carcinoma gallbladder, periampullary carcinoma, etc., and traumatic etiologies. It has been observed that the most common causes of surgical obstructive jaundice are malignant lesions. ${ }^{1,2}$ - Table 1 highlights the various important causes of obstructive jaundice.

\section{Indications for PTBD}

Percutaneous transhepatic biliary drainage (PTBD) may be performed for both benign and malignant causes. ${ }^{3}$ It can be used as a palliative procedure in nonoperable patients, a bridging procedure for further biliary stenting, or as an emergency procedure for clinically unstable patients presenting with acute severe cholangitis. - Table 2 highlights the indications for PTBD.

(C)2020 by Indian Society of Vascular and Interventional Radiology
License terms

$($ (1) $\Theta \circledast$ 
Table 1 Causes of obstructive jaundice

\begin{tabular}{|c|c|}
\hline Malignant etiologies & Benign etiologies \\
\hline - Gallbladder carcinoma & - Choledocholithiasis \\
\hline - Carcinoma head of pancreas & $\begin{array}{l}\text { - Postcholecystectomy } \\
\text { strictures }\end{array}$ \\
\hline - Cholangiocarcinoma & - Choledochal cyst \\
\hline - Periampullary carcinoma & - Chronic pancreatitis \\
\hline - Duodenal carcinoma & - Posttraumatic strictures \\
\hline - Hepatic metastases & \\
\hline $\begin{array}{l}\text { - Extrinsic compression due } \\
\text { to malignant lymph nodes }\end{array}$ & \\
\hline
\end{tabular}

Table 2 Indication for PTBD procedure

\begin{tabular}{|l|}
\hline (A) Biliary drainage \\
\hline (B) Biliary access route establishment for: \\
\hline Dilatation of biliary strictures \\
\hline Stent placement \\
\hline Stone removal \\
\hline Endoluminal therapy \\
\hline Tissue sampling \\
\hline (C) Management of postoperative complications \\
\hline
\end{tabular}

Abbreviation: PTBD, percutaneous transhepatic biliary drainage.

\section{Role of Imaging before PTBD}

Specific questions that a radiologist should answer on imaging prior to PTBD include:

- Is there obstruction?

- Which modality is the best to ascertain biliary obstruction?

- What is the level of obstruction?

- What is the cause of obstruction?

- What is the extent of disease?

- Is PTBD amenable?

Besides, imaging also helps in planning the procedure by addressing:

- Variants of bile ductal anatomy.

- Postoperative appearances that are relevant to PTBD.

\section{Is there Obstruction?}

Benign strictures have a broad spectrum of presentation ranging from subclinical disease to jaundice, pruritus, and cholangitis. Imaging diagnosis of biliary obstruction is straightforward in most cases. The normal intrahepatic bile ducts may measure up to $2 \mathrm{~mm}$ or less than $40 \%$ of the diameter of the accompanying portal vein branch. ${ }^{6}$ In certain situations, particularly postcholecystectomy and hepaticojejunostomy (HJ) strictures, there may be minimal

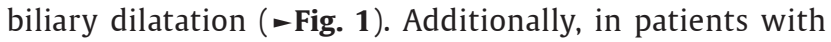
$\mathrm{HJ}$ strictures, the presence of pneumobilia may preclude a comprehensive evaluation of biliary tree on ultrasound (US). The clinical features may be much more pronounced compared with imaging findings. In these situations,

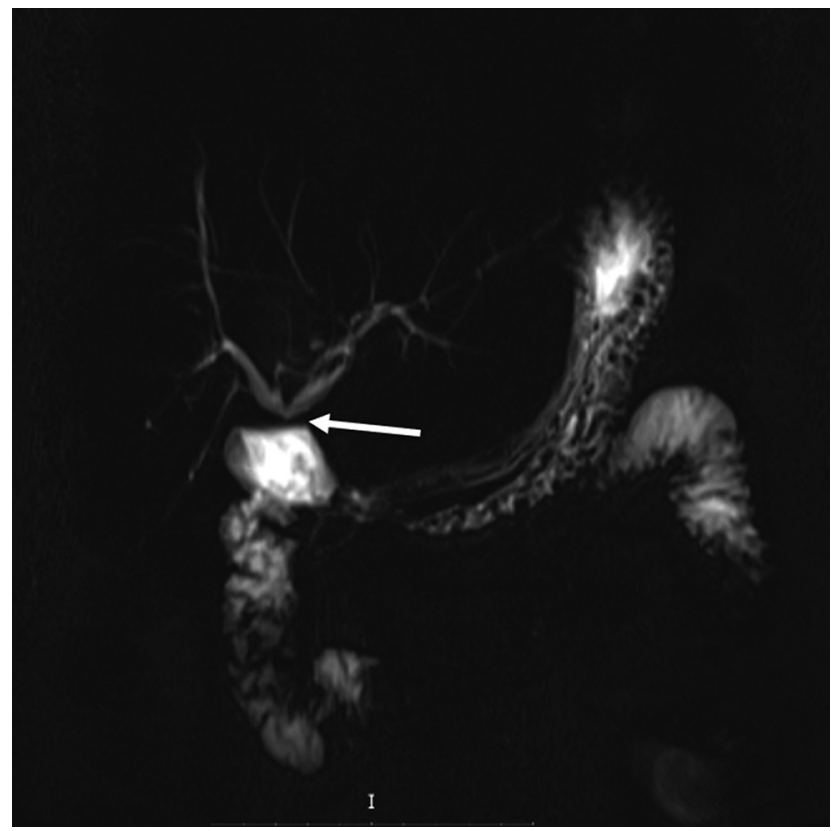

Fig. 1 MRCP images show a hepaticojejunostomy $(\mathrm{HJ})$ stricture with mild bilateral intrahepatic biliary radicle dilatation (arrow). This patient underwent successful PTBD and balloon dilatation of the stricture. Patients with $\mathrm{HJ}$ strictures may be asymptomatic and have minor derangements in liver functions. However, they are at risk of recurrent cholangitis and secondary biliary cirrhosis. Imaging, particularly, MRCP helps establish a diagnosis of stricture at HJ site. PTBD, percutaneous transhepatic biliary drainage; MRCP, magnetic resonance cholangiopancreatography.

biliary dilatation may not be detected on US and computed tomography (CT). Although MRCP has a higher sensitivity for detection of biliary dilatation, in the presence of pneumobilia may render the evaluation of biliary system difficult. $^{7}$ In most of the patients with malignant extra hepatic biliary obstructive (EHBO), the diagnosis of biliary obstruction is easily made on US. ${ }^{6}$ However, in patients who have undergone ERCP and stenting or EUS-biliary drainage, the evaluation may be challenging due to the presence of pneumobilia.?

\section{Which Modality is the Best to Ascertain Biliary Obstruction?}

Ultrasound is the initial imaging test of choice for evaluation of biliary system as it is widely available, relatively inexpensive, and has high sensitivity and specificity for detection of biliary dilatation ${ }^{8}$ ( Fig. 2). Additionally, it is highly accurate in the evaluation of gallbladder abnormalities, including cholelithiasis. ${ }^{9}$ The disadvantages are the user dependence, difficulty in evaluation of obese patients, inability to evaluate the lower end of common bile duct (CBD), and the periampullary region. ${ }^{10}$ EUS has high accuracy in the assessment of the lower end of the CBD and the periampullary region ${ }^{11}(-$ Fig. 3). CT has a high sensitivity and specificity in the local staging of malignant disease involving the biliary tree $^{12}$ ( - Fig. 4). However, it is not accurate in differentiation of malignant from benign strictures. ${ }^{11}$ MRCP is highly accurate in assigning the level of obstruction ${ }^{10}$ (-Fig. 5). Contrast-enhanced MRI and diffusion-weighted MRI 

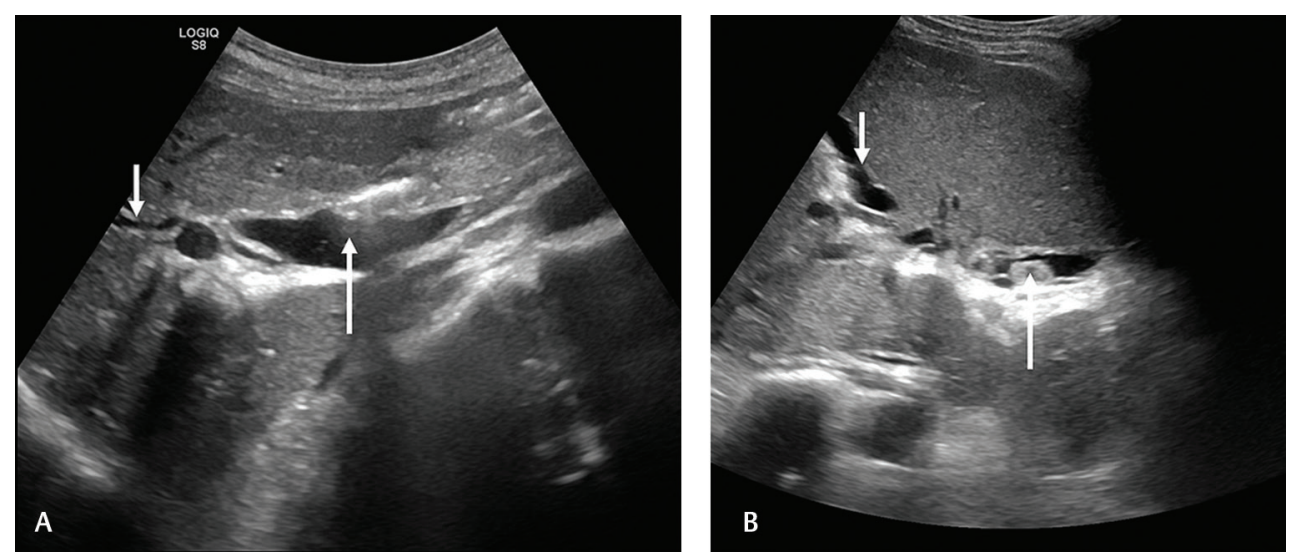

Fig. 2 Ultrasound image shows dilated common bile duct with benign stricture at lower end (long arrow, A) with minimal intrahepatic biliary radicle dilatation. Ultrasound image in another patient shows dilated intrahepatic biliary radicles (arrow) with calculus in the dilated common bile duct (long arrow, B). Both these patients were referred for PTBD in view of moderate cholangitis; however, imaging identification of the cause and site of stricture led to successful ERCP in both these patients. PTBD, percutaneous transhepatic biliary drainage; ERCP, endoscopic retrograde cholangiopancreatography.

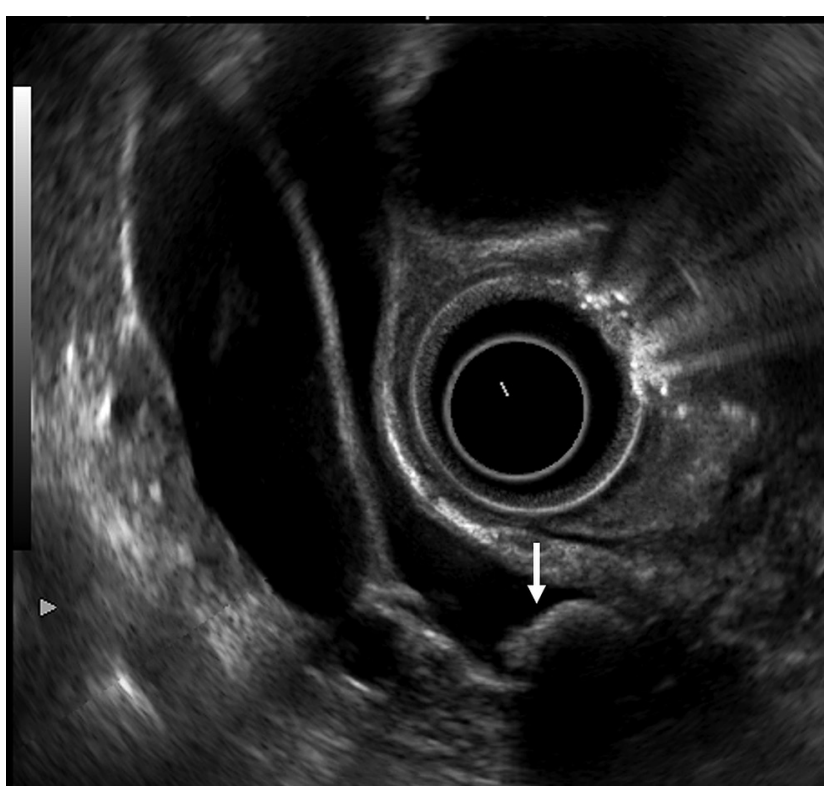

Fig. 3 Endoscopic ultrasound image shows a calculus impacted at the lower end of common bile duct (arrow). Endoscopic ultrasound has a complimentary role in imaging evaluation prior to biliary drainage. increase the confidence of differentiation of benign from malignant biliary strictures ${ }^{13}$ (-Fig. 6). When appropriately utilized, the imaging modalities discussed above provide a road map to decide the feasibility and approach to perform the biliary drainage.

\section{What is the Level of Obstruction?}

All the previous imaging available with the patient should be reviewed. The aim is to classify the location of biliary obstruction as proximal or distal. This will help in deciding the preferred access for biliary drainage. In general, for distal biliary obstruction (beyond the hilum), ERCP is preferred. ${ }^{14}$ For proximal biliary obstruction, PTBD is preferred..$^{14}$ In case of proximal obstruction, the documentation of patency of the primary confluence is also essential as separation of right and left hepatic ducts may mandate a bilateral PTBD in certain situations. The patency of the confluence will also affect the technique of biliary stenting. Patients with obstruction following biliary-enteric anastomosis are also suitable for PTBD. - Figs. $\mathbf{7}$ to $\mathbf{1 0}$ highlight the classification of benign and malignant strictures based on the site of involvement.
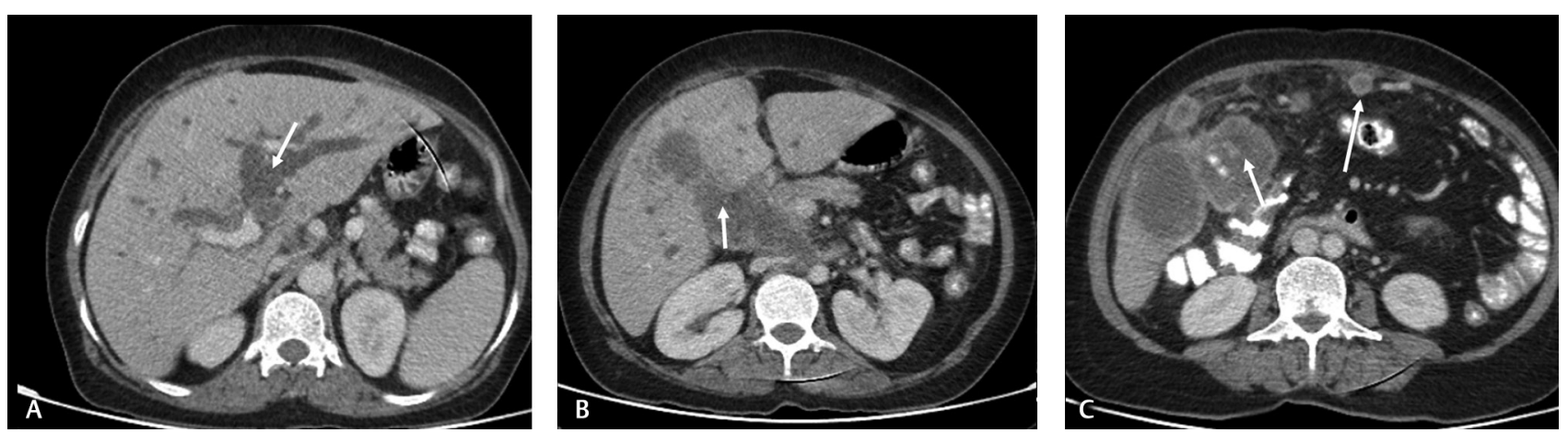

Fig. 4 CT images show intrahepatic biliary radicle dilatation (arrow, A) caused by a mass in the gallbladder (arrow, B). In addition to the gallbladder mass (arrow, C), there are multiple omental deposits (long arrow, C). In view of unresectable disease, this patient underwent PTBD and was planned for metallic stenting. PTBD, percutaneous transhepatic biliary drainage. 

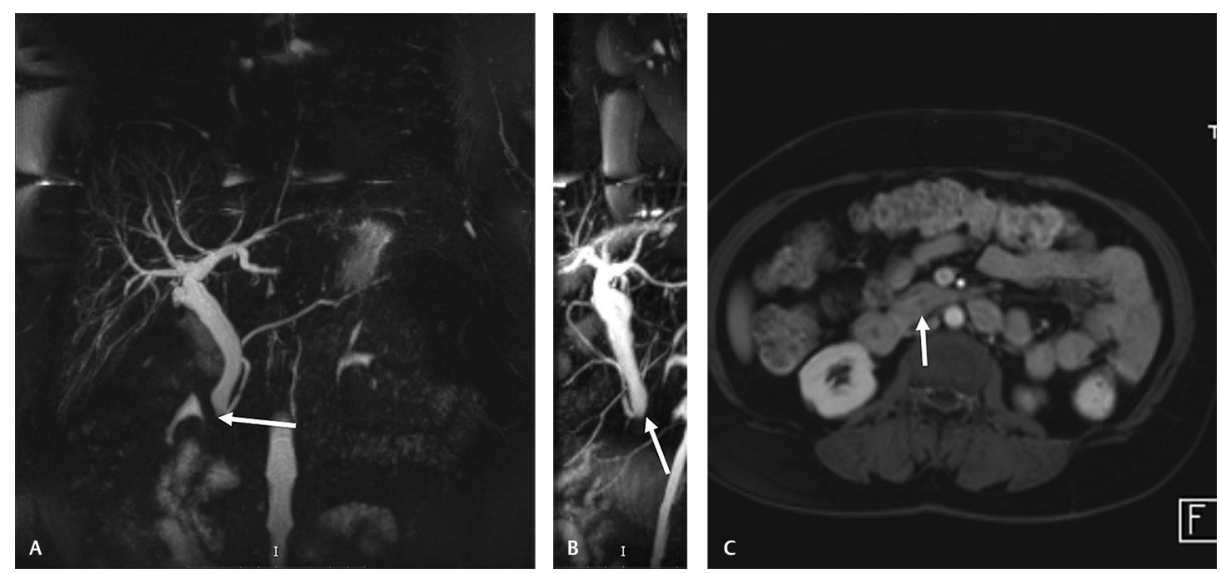

Fig. $5 \mathrm{MRI}$ and MRCP images show dilatation of the intrahepatic ducts and common bile duct till the lower end (arrows, $\mathbf{A}$ and $\mathbf{B}$ ). No definite mass could be visualized in the periampullary region (arrow, C). In view of lower end block, this patient underwent ERCP with brush cytology and diagnosis of periampullary carcinoma was established. ERCP, endoscopic retrograde cholangiopancreatography; MRCP, magnetic resonance cholangiopancreatography; MRI, magnetic resonance imaging.
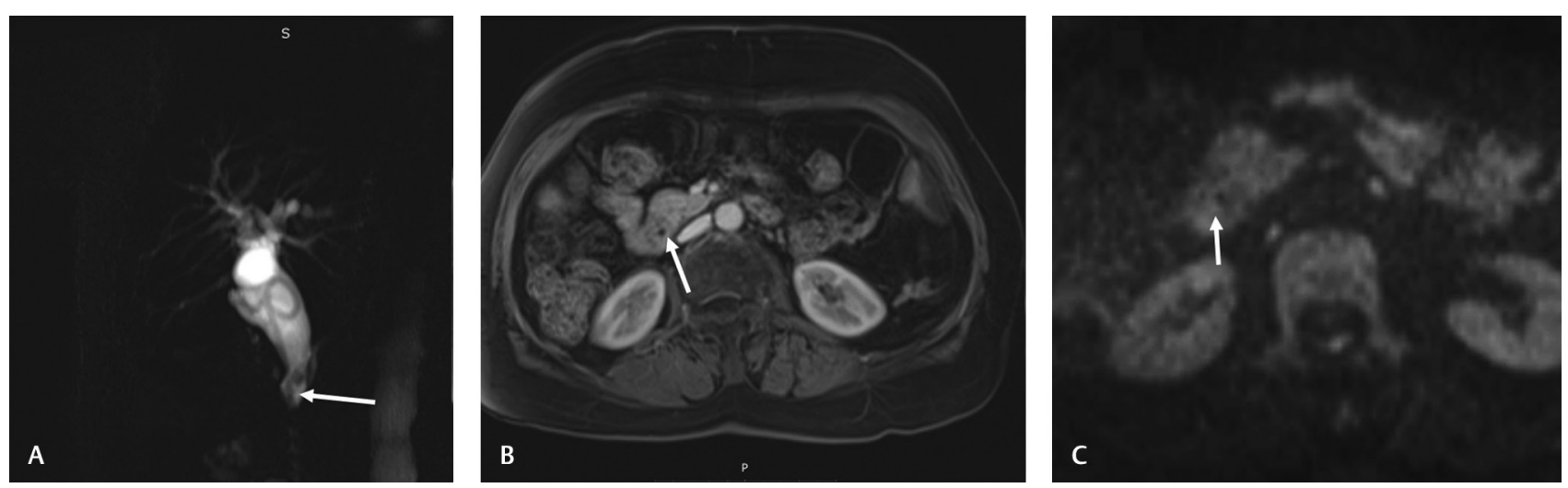

Fig. 6 MRCP with contrast-enhanced MRI and diffusion-weighted MRI shows obstruction at the lower end of CBD (arrow, A). There is thick mural enhancement (arrow, B) and diffusion restriction (arrow, C) suggesting a malignant stricture. Diffusion weighted imaging helps detect these subtle lesions. MRCP, magnetic resonance cholangiopancreatography; MRI, magnetic resonance imaging; CBD, common bile duct.
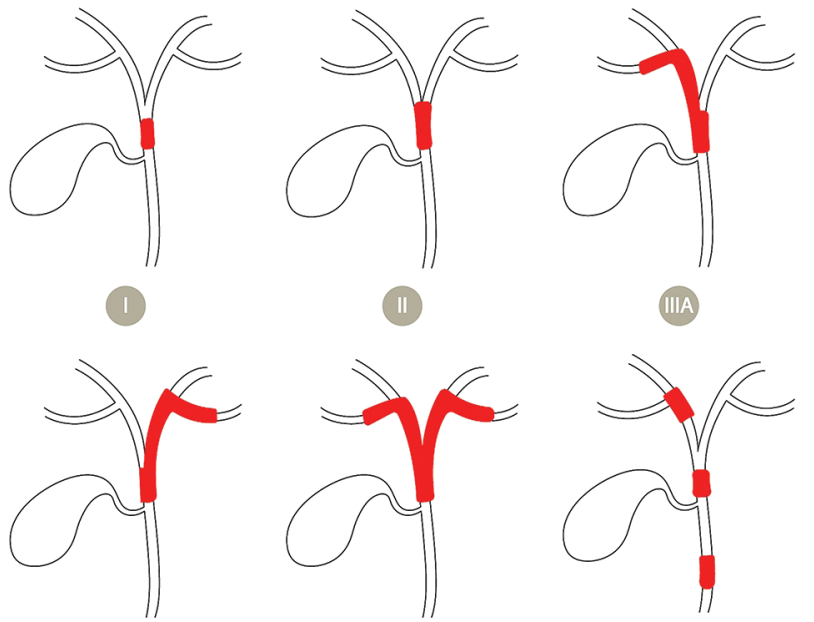

(11)
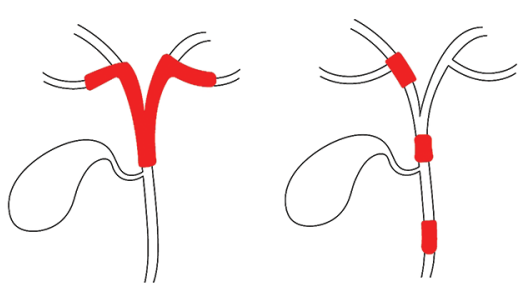

IIIB

(V)

Fig. 7 Bismuth-Corlette classification of perihilar cholangiocarcinoma. (I) Primary confluence not involved, (II) primary confluence involved, secondary confluence not involved; (IIla) involvement of right secondary confluence; (IIIb) involvement of the left secondary confluence; (IV) involvement of bilateral secondary confluence; (IV) multiple strictures.

\section{What is the Cause of Obstruction?}

It is essential to differentiate between benign and malignant causes of biliary obstruction. Benign causes like Mirrizzi's syndrome are best treated with surgical intervention. Benign periampullary strictures such as those caused by pancreatitis are suitable for sphincterotomy rather than percutaneous drainage. Strictures in the setting of biliary-enteric anastomosis and proximal benign strictures are candidates for percutaneous drainage if surgical resection is not possible. Certain imaging features favor malignant etiology, although this may be challenging and may require more comprehensive evaluation ( - Table 3 ). ${ }^{15,16}$

\section{What is the Extent of Disease?}

It is essential to stage the malignancy and ascertain the resectability of the disease. Patients amenable for resection should be considered for surgical interventions first unless these have been complicated by cholangitis. Although a matter of debate, according to a recent review, preoperative biliary drainage is not usually indicated for middle-distal obstruction. ${ }^{14}$ On the other hand, proximal obstruction in patients who are potential candidates for major liver 
resection requires preoperative drainage in most of the cases. ${ }^{14}$ Patients with unresectable or metastatic disease are considered for palliative biliary drainage and metallic stenting. The local extent of the disease may also affect the decision. If the secondary confluences are involved, then the contralateral side should be preferred. The decision to perform drainage in patients with involvement of bilateral secondary confluence should be made per case basis. The ductal system draining the maximum volume of functional residual liver should be preferred as more than $25 \%$ of the
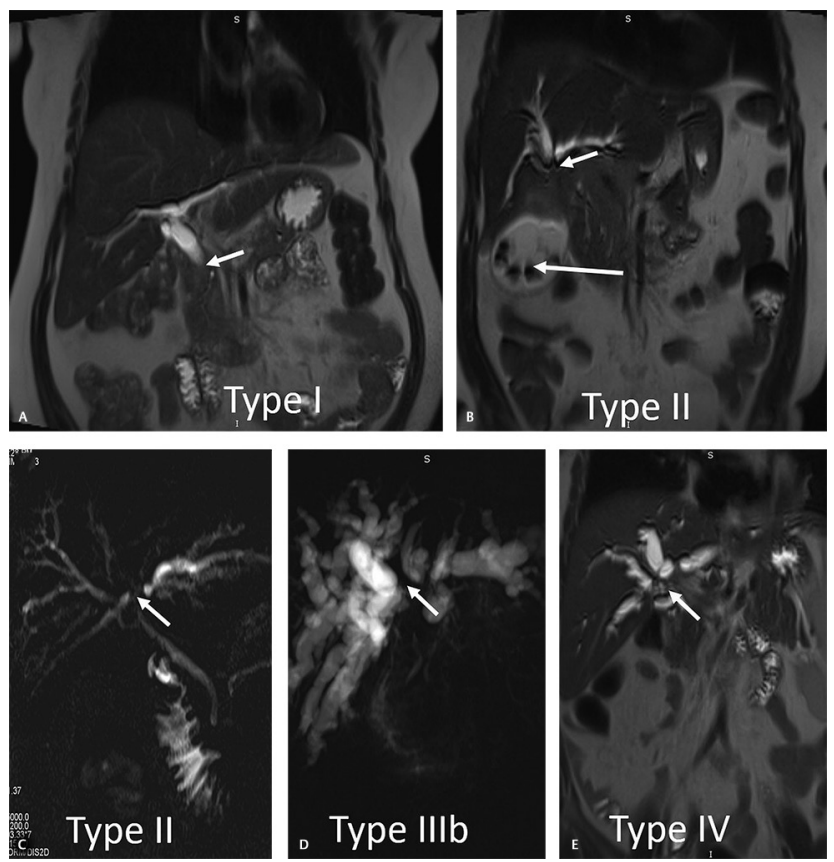

Fig. $8 \mathrm{MRI} / \mathrm{MRCP}$ images depicting Bismuth-Corlette classification. (I) Block at the common hepatic duct/common bile duct (arrow, A); (II) primary confluence is involved (arrow, B) by a mass at the neck of the gallbladder (long arrow, B); (II) MRCP image showing separation of the right and left ductal system (arrow, C); (IIIb) MRCP image showing involvement of the primary and left secondary confluence (arrow, D); (IV) involvement of bilateral secondary confluences (arrow, E). MRCP, magnetic resonance cholangiopancreatography; MRI, magnetic resonance imaging. liver should be drained to relieve jaundice and pruritis. ${ }^{6}$ The right anterior ducts provide easier route for internalization and stenting.

\section{Is PTBD Amenable?}

PTBD requires dilatation of the ductal system for the intervention radiologist to puncture the duct. For routine purposes, peripheral ductal dilatation of more than $2 \mathrm{~mm}$ is desirable. However, under expert hands, nondilated or minimally dilated systems can also be punctured using micropuncture sets and other techniques (opacification of the ductal system through an indwelling T-tube, use of the T-tube tract, computed tomography (CT) guidance, and percutaneous cholecystotomy). ${ }^{17,18}$ The presence of moderate to gross ascites has been reported to increase the risk of bleeding and biliary peritonitis. ${ }^{19-21}$ The presence of a

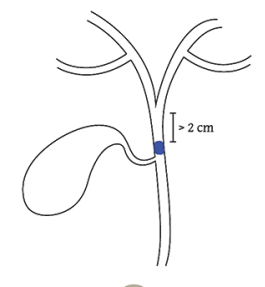

(1)

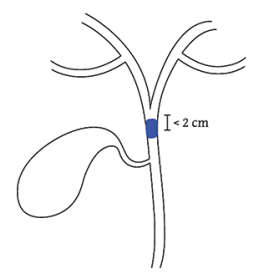

(II)

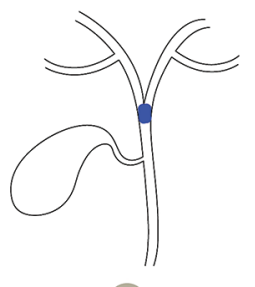

(III)

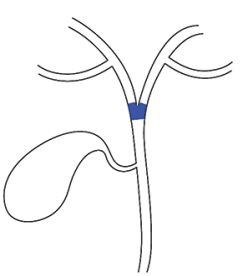

(V)

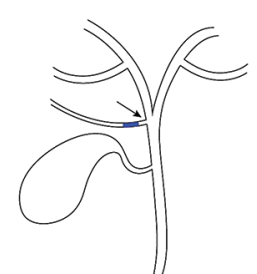

(
Fig. 9 Bismuth's classification of benign biliary strictures. (I) Stricture more than $2 \mathrm{~cm}$ from the confluence; (II) stricture less than $2 \mathrm{~cm}$ from the confluence and not involving the confluence; (III) stricture involving the confluence, but the confluence is patent; (IV) the confluence is not patent; (V) stricture of the aberrant right hepatic duct.
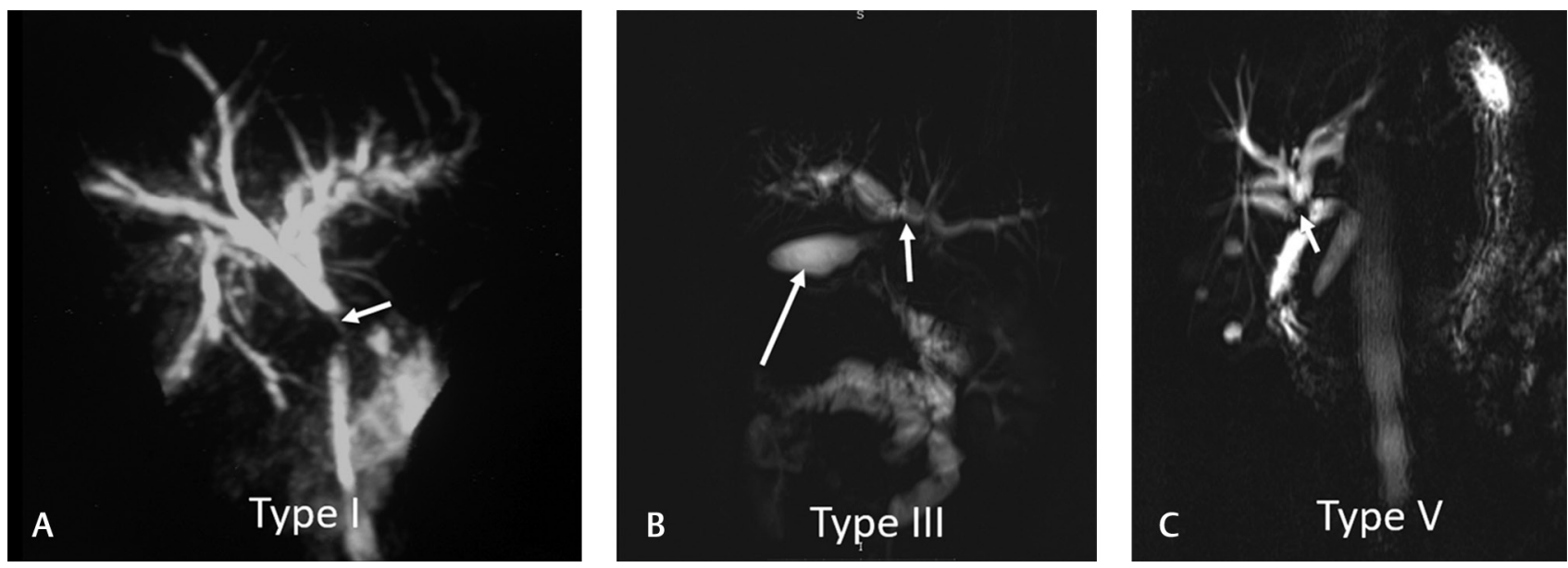

Fig. $10 \mathrm{MRI} / \mathrm{MRCP}$ images depicting the Bismuth's classification for benign strictures. (I) Stricture of the common bile duct (arrow, $\mathbf{A}$ ); (III) primary confluence is involved (arrow, B) and there is a postcholecystectomy collection in the perihepatic location (long arrow, B); ( $\mathrm{V}$ ) stricture of the aberrant right hepatic duct (arrow, C). MRCP, magnetic resonance cholangiopancreatography; MRI, magnetic resonance imaging. 
Table 3 MRCP imaging features favoring malignant etiology

\begin{tabular}{|l|}
\hline - Asymmetrical thickening \\
\hline - Long-segment involvement (> $15 \mathrm{~mm})$ \\
\hline - Enhancement of the wall \\
\hline - Luminal irregularity \\
\hline - Indistinct outer margin \\
\hline - Ancillary features including lymph nodes, ascites, and liver \\
lesions \\
\hline
\end{tabular}

Abbreviation: MRCP, magnetic resonance cholangiopancreatography.

distended gallbladder should be recorded as in some situations when all attempts to drain the biliary radicles have failed, and drainage may be achieved via percutaneous cholecystostomy. ${ }^{22}$

\section{Planning for Intervention: Variant Biliary Anatomy}

It is not uncommon to find variant biliary ductal anatomy (-Fig. 11). MRCP is the imaging method of choice for evaluating biliary anatomy. The preoperative assessment of biliary anatomy helps in deciding the routes of drainage. ${ }^{23}$ This information is also helpful in guiding internalization, particularly in difficult cases.

\section{Planning for Intervention: Postsurgical Biliary Anatomy} Biliary-enteric anastomosis is performed for a variety of benign and malignant diseases. ${ }^{24}$ The most common type of biliary-enteric anastomosis is HJ. During HJ, usually a loop of jejunum is anastomosed to allow drainage of both

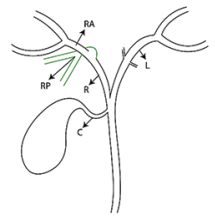

(1)

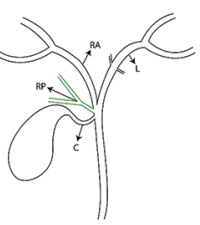

(38

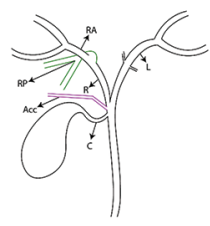

5

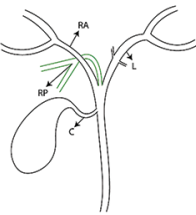

(2)

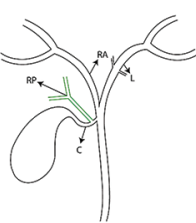

(3C)

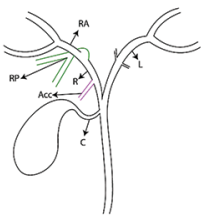

(5B

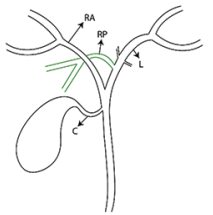

(3A
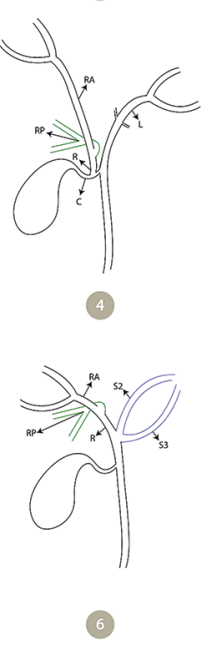

Fig. 11 Variations in the anatomy of intrahepatic bile ducts. C: cystic duct, L: left hepatic duct, R: right hepatic duct, RA: right anterior duct, RP: right posterior duct, S1: segment 1 duct, S2: segment 2 duct. right and left hepatic ducts. Less common, an anastomosis may be performed draining right and left ducts separately into the jejunal loop at two different sites ( - Fig. 12). Less common types of biliary-enteric anastomosis are choledochoduodenostomy, portojejunostomy, and cholecystoenteric bypass. ${ }^{24}$

The performance of various imaging modalities in assessment of patients with EHBO has been compared in multiple studies ( - Table 4) . $^{25-30}$ It had been found that MRI/MRCP and EUS provide better diagnostic yield in terms of detection of obstruction and ascertaining the level of obstruction.

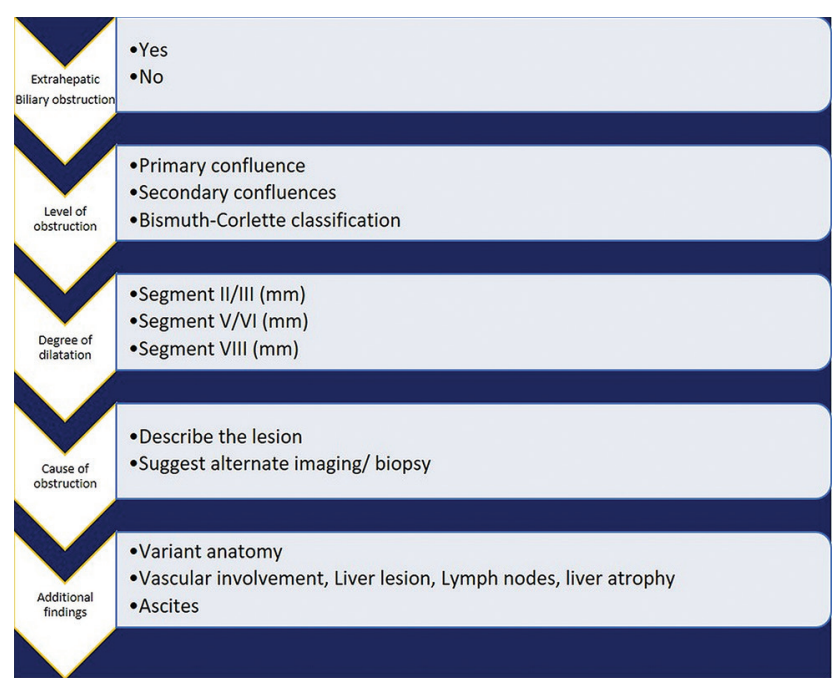

Fig. 12 Proposed format for reporting of imaging findings in patients with biliary obstruction being planned for biliary drainage.

Table 4 Diagnostic accuracy of various imaging tests for extrahepatic biliary obstruction

\begin{tabular}{|c|c|}
\hline Modality & Accuracy (\%) \\
\hline \multicolumn{2}{|l|}{ USG } \\
\hline Detection of obstruction & $73-95$ \\
\hline Level of obstruction & $27-95$ \\
\hline Cause of obstruction & $22-88$ \\
\hline \multicolumn{2}{|l|}{ CT } \\
\hline Detection of obstruction & $90-95$ \\
\hline Level of obstruction & $81-94$ \\
\hline Cause of obstruction & $88-92$ \\
\hline \multicolumn{2}{|l|}{ MRI/MRCP } \\
\hline Detection of obstruction & 99 \\
\hline Level of obstruction & 99 \\
\hline Cause of obstruction & 85 \\
\hline \multicolumn{2}{|l|}{ EUS } \\
\hline Choledocholithiasis & 99 \\
\hline Malignant strictures & 90 \\
\hline Benign strictures & 92 \\
\hline
\end{tabular}

Abbreviation: USG, ultrasonography; CT, computed tomography; MRI/ MRCP, magnetic resonance imaging/ magnetic resonance cholangiopancreatography; EUS, endoscopic ultrasound. 
It is useful to follow a standard format for reporting imaging of patients presenting with obstructive jaundice (-Fig. 12).

\section{Conclusion}

In conclusion, detailed review of imaging is vital to the success of biliary drainage in patients with surgical obstructive jaundice. It plays an important role in deciding whether to undertake a percutaneous or endoscopic drainage and in patients undergoing PTBD; it helps in allowing adequate planning of the procedure.

\section{Financial Disclosure}

None declared.

\section{Conflicts of Interest}

None declared.

\section{References}

1 Selvasekaran R, Nagalakshmi G, Anandan H. Clinical spectrum of presentation of obstructive jaundice in inflammation, stone disease and malignancy. Int J Sci Stud 2017;5:10-14

2 Padhy B, Murmu D, Samal D, Jha S. Clinical study of surgical jaundice: an institutional experience. Int Surg J 2018;5:138-142

3 Yadav A, Condoti NK, Mukund A, et al. Percutaneous transhepatic biliary interventions. J Clin Interv Radiol ISVIR 2018;2:27-37

4 Patel NA, Parekh H, Vasavada DP, Mehta SG, Porecha MM, Shah J. A pictorial essay- imaging in surgical jaundice. Indian J Radiol Imaging 2006;16(1):75-82

5 Katabathina VS, Dasyam AK, Dasyam N, Hosseinzadeh K. Adult bile duct strictures: role of MR imaging and MR cholangiopancreatography in characterization. Radiographics 2014;34(3):565-586

6 Skoczylas K, Pawełas A. Ultrasound imaging of the liver and bile ducts - expectations of a clinician. J Ultrason 2015;15(62):292-306

7 Irie H, Honda H, Kuroiwa T, et al. Pitfalls in MR cholangiopancreatographic interpretation. Radiographics 2001;21(1):23-37

8 Yarmenitis SD. Ultrasound of the gallbladder and the biliary tree. Eur Radiol 2002;12(2):270-282

9 Shea JA, Berlin JA, Escarce JJ, et al. Revised estimates of diagnostic test sensitivity and specificity in suspected biliary tract disease. Arch Intern Med 1994;154(22):2573-2581

10 Yeh BM, Liu PS, Soto JA, Corvera CA, Hussain HK. MR imaging and CT of the biliary tract. Radiographics 2009;29(6):1669-1688

11 McMahon CJ. The relative roles of magnetic resonance cholangiopancreatography (MRCP) and endoscopic ultrasound in diagnosis of malignant common bile duct strictures: a critically appraised topic. Abdom Imaging 2008;33(1):10-13

12 Singh A, Gelrud A, Agarwal B. Biliary strictures: diagnostic considerations and approach. Gastroenterol Rep (Oxf) 2015;3(1):22-31

13 Cui XY, Chen HW. Role of diffusion-weighted magnetic resonance imaging in the diagnosis of extrahepatic cholangiocarcinoma. World J Gastroenterol 2010;16(25):3196-3201
14 Iacono C, Ruzzenente A, Campagnaro $\mathrm{T}$, Bortolasi L, Valdegamberi A, Guglielmi A. Role of preoperative biliary drainage in jaundiced patients who are candidates for pancreatoduodenectomy or hepatic resection: highlights and drawbacks. Ann Surg 2013;257(2):191-204

15 Kim JY, Lee JM, Han JK, et al. Contrast-enhanced MRI combined with MR cholangiopancreatography for the evaluation of patients with biliary strictures: differentiation of malignant from benign bile duct strictures. J Magn Reson Imaging 2007;26(2):304-312

16 Park MS, Kim TK, Kim KW, et al. Differentiation of extrahepatic bile duct cholangiocarcinoma from benign stricture: findings at MRCP versus ERCP. Radiology 2004;233(1):234-240

17 Kühn JP, Busemann A, Lerch MM, Heidecke CD, Hosten N, Puls R. Percutaneous biliary drainage in patients with nondilated intrahepatic bile ducts compared with patients with dilated intrahepatic bile ducts. AJR Am J Roentgenol 2010;195(4):851-857

18 Gupta P, Maralakunte M, Rathee S, et al. Percutaneous transhepatic biliary drainage in patients at high risk for adverse events: experience from a tertiary care referral centre. Abdom Radiol 2019. [epub ahead of print] Doi:10.1007/s000261-091-02344-1

19 Saad WE, Wallace MJ, Wojak JC, Kundu S, Cardella JF. Quality improvement guidelines for percutaneous transhepatic cholangiography, biliary drainage, and percutaneous cholecystostomy. J Vasc Interv Radiol 2010;21(6):789-795

20 Bonshock R, McLaughlin S, Duncan C, et al. Complication rates of percutaneous biliary drainage in the presence of ascites. J Vasc Interv Radiol 2017;28:S54

21 Patel V, McLaughlin SW, Shlansky-Goldberg R, et al. Complication rates of percutaneous biliary drainage in the presence of ascites. Abdom Radiol (NY) 2019;44(5):1901-1906

22 Gupta P, Kalra N, Kumar A, Kochhar R, Gupta V, Khandelwal N. Balloon dilatation of a benign biliary stricture through a T-tube tract. Indian J Radiol Imaging 2015;25(1):21-24

23 Funaki B. Percutaneous biliary drainage. Semin Intervent Radiol 2007;24(2):268-271

24 Boraschi P, Donati F. Biliary-enteric anastomoses: spectrum of findings on Gd-EOB-DTPA-enhanced MR cholangiography. Abdom Imaging 2013;38(6):1351-1359

25 Romagnuolo J, Bardou M, Rahme E, Joseph L, Reinhold C, Barkun AN. Magnetic resonance cholangiopancreatography: a meta-analysis of test performance in suspected biliary disease. Ann Intern Med 2003;139(7):547-557

26 Morimoto K, Shimoi M, Shirakawa T, et al. Biliary obstruction: evaluation with three-dimensional MR cholangiography Radiology 1992;183(2):578-580

27 Dewbury KC, Joseph AE, Hayes S, Murray C. Ultrasound in the evaluation and diagnosis of jaundice. $\mathrm{Br} \mathrm{J}$ Radiol 1979;52(616):276-280

28 Chan YL, Chan AC, Lam WW, et al. Choledocholithiasis: comparison of MR cholangiography and endoscopic retrograde cholangiography. Radiology 1996;200(1):85-89

29 Mendler MH, Bouillet P, Sautereau D, et al. Value of MR cholangiography in the diagnosis of obstructive diseases of the biliary tree: a study of 58 cases. Am J Gastroenterol 1998;93(12):2482-2490

30 Ferrari FS, Fantozzi F, Tasciotti L, Vigni F, Scotto F, Frasci P. US, MRCP, CCT and ERCP: a comparative study in 131 patients with suspected biliary obstruction. Med Sci Monit 2005;11(3):MT8-MT18 